\title{
Music of the Spheres
}

\author{
Charlotte Jarvis \\ Visual Artist \\ 47 The Ridgeway \\ London N3 2PG \\ UK \\ charlotte@artforeating.com
}

\author{
Nick Goldman \\ European Molecular Biology Laboratory \\ European Bioinformatics Institute \\ Wellcome Trust Genome Campus \\ Hinxton CB10 1SD, UK \\ goldman@ebi.ac.uk
}

\section{INTRODUCTION}

Music of the spheres utilises new bioinformatics technology by Dr Nick Goldman to store a new musical MP3 recording by the Kreutzer Quartet on DNA molecules. The DNA has been suspended in soap solution and will be used by visual artist Charlotte Jarvis to create performances and installations filled with bubbles. The 'recording' will fill the air, pop on visitors' skin, and literally bathe the audience in music.

\section{ENCODING DIGITAL DATA IN DNA}

In response to the growing challenge of storing vast quantities of biological data generated by biomedical research, Dr Nick Goldman and EMBLEuropean Bioinformatics Institute (EMBL-EBI) have developed a method to encode digital files in DNA itself.

Nick's method mimics how computers store information digitally using 0 's and 1's by coding data into the bases $(A, C, T$ and $G$ ) that form DNA sequences. His goal is a system that will safely store the equivalent of one million CDs in a gram of DNA for 10,000 years.

\subsection{Musical DNA Recording}

Nick and Charlotte have been working together for the past two years on an art project responding to this technology. Byron:

"There's music in the sighing of a reed/ There's music in the gushing of a rill/ There's music in all things, if men had ears/ The earth is but the music of the spheres".

Charlotte and Nick see similarity between Byron's idea of an underlying universal melody and contemporary understanding of DNA as universal code for life. They aim is to create a series of moving visual and musical experiences that explore the scope and future ubiquity of DNA technologies.
Charlotte, Nick and The Kreutzer Quartet have encoded the central movement of a new musical MP3 recording as a sequence of DNA. The whole composition comprises three movements and it is just the second of these (the central movement) that has been stored on DNA molecules. The original MP3 file has been deleted so that the recording of the second movement now only exists in the form of DNA.

In order to listen to this part of the recording the DNA needs sequencing. Right now only a relatively small part of the scientific community has the resources to do this; however, by the end of this year the 'minION' and other similar devices are due for release - the size of a packet of chewing gum, these gadgets plug into a USB drive and can sequence DNA in your own home. Over the next few years the central movement of the composition will become widely accessible - it will be unlocked by technological advancement.

\subsection{Bubbles}

For exhibitions the DNA will be suspended in soap solution and used to create silent installations filled with bubbles. Just as music fills the air, so will the bubbles, popping on the visitors' skin and literally bathing them in music. The bubbles will be accompanied by a video projection showing the musicians playing in the server room of the EMBLEBI. Print material will document the process and a prototype MINion will be hooked up to a laptop to sequence the DNA and reveal the MP3 file stored within it.

In the performances Kreutzer Quartet, will play the full-length composition. During the passage of the second movement the stage will fall silent. The music will be released into the auditorium in the form of bubbles. The performances will be accompanied by film projection and a discussion about the project. 


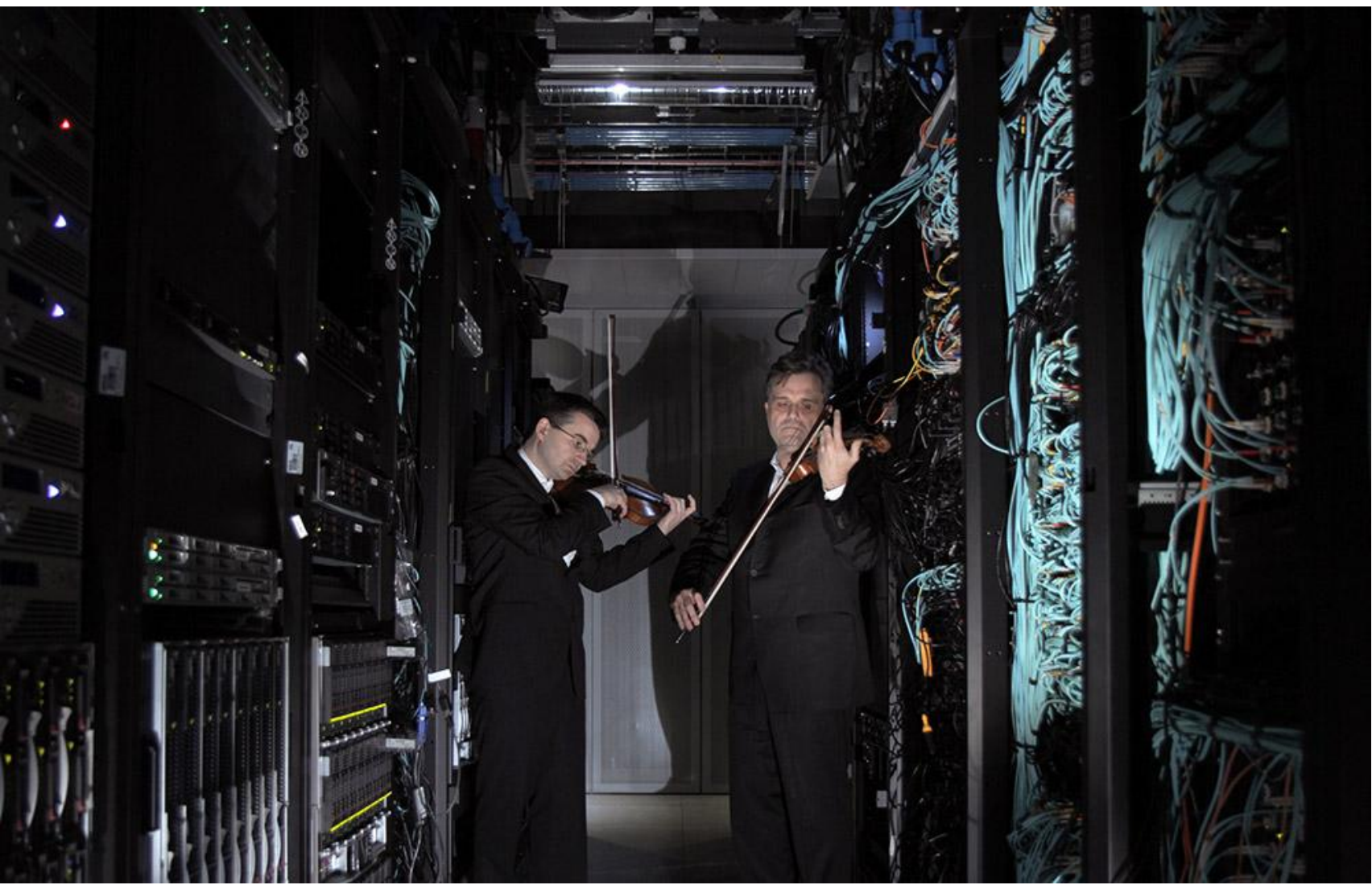

Figure 1: Film Still: Kreutzer Quartet playing in one of the server rooms at the European Bioinformatics Institute

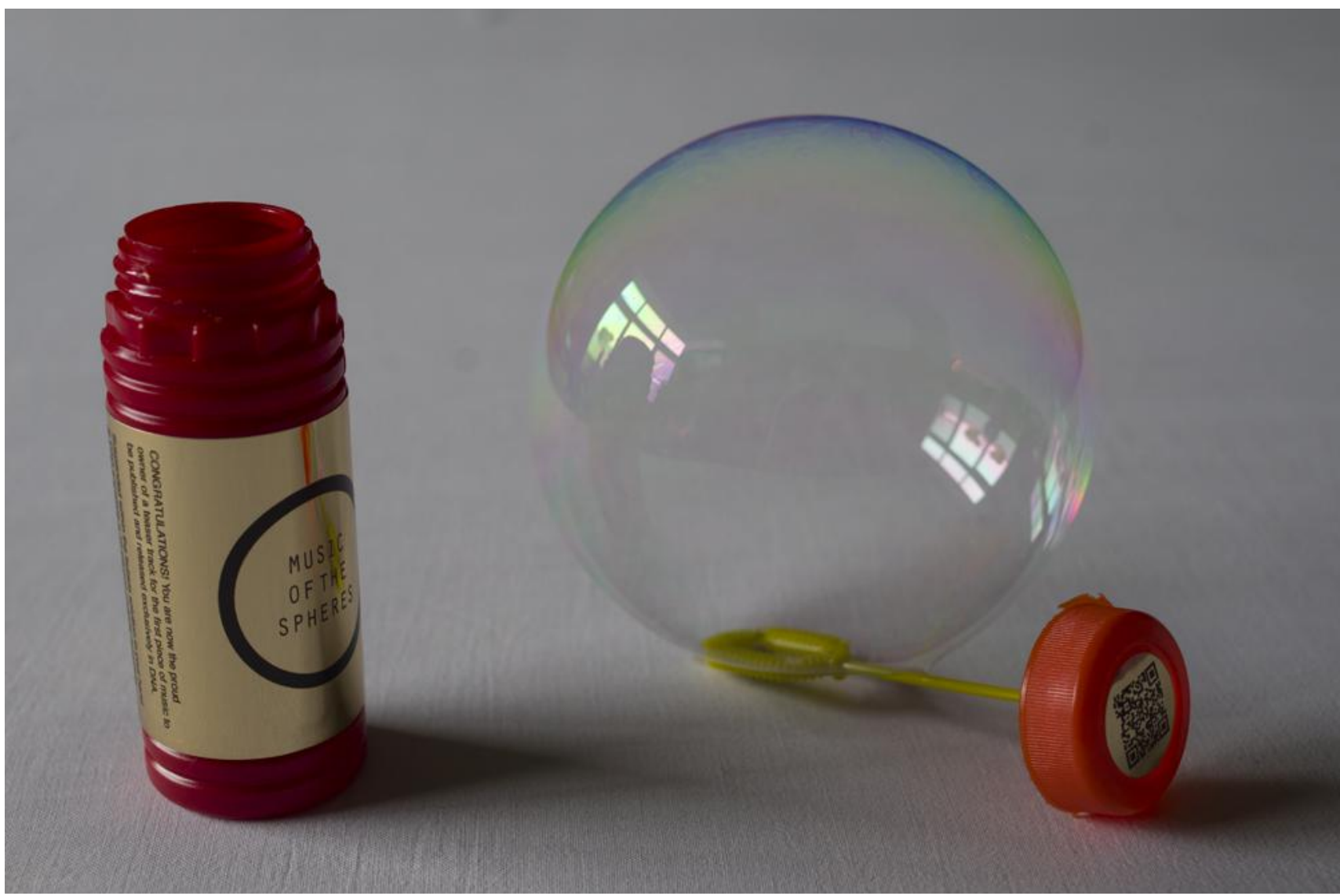

Figure 2: Bubbles: The DNA molecules storing the MP3 recording have been suspended in soap solution 